\title{
Decision-making trends in quality management: a literature review about lndustry 4.0
}

\author{
Lucas Schmidt Goecks ${ }^{\mathrm{a} *}$ (D), Alex Almeida dos Santos ${ }^{\mathrm{a}}$ (D), André Luis Korzenowski ${ }^{\mathrm{a}}$ \\ aUniversidade do Vale do Rio dos Sinos, São Leopoldo, RS, Brasil \\ *lucas_goecks@hotmail.com
}

\begin{abstract}
Paper aims: Due to the scarcity of research on current scenarios of quality management in the $21^{\text {st }}$ century, this article addresses the concepts of big data and Industry 4.0 for decision-making in quality control.

Originality: This article contributes to completing categorizations and answering questions that have been previously suggested.
\end{abstract}

Research method: This study presents a systematic literature review and qualitative data. The methodological framework shows the process of the selection and review of articles according to their alignment with the objective of the study.

Main findings: Seventeen articles were selected to structure the study and were classified according the categories presented in the literature. The vast majority of the research gaps pointed out in previous review have been filled since their publication.

Implications for theory and practice: In addition, this article presents new gaps to be filled and complements the literature and concepts about quality management and lndustry 4.0.

Keywords

Quality management. Decision-making. Industry 4.0. Big data.

How to cite this article: Goecks, L. S., Santos, A. A., \& Korzenowski, A. L. (2020). Decision-making trends in quality management: a literature review about Industry 4.0. Production, 30, e20190086. https://doi.org/10.1590/0103-6513.20190086.

Received: July 29, 2019; Accepted: Feb. 28, 2020.

\section{Introduction}

Industry is part of an economy that produces highly mechanized and automated materials. Since the beginning of industrialization, technological leaps have led to paradigmatic changes called "industrial revolutions": first, in the field of mechanization; second, in the intensive use of electric energy; and third, in the widespread use of scanning. Based on advanced digitization inside of factories and the combination of Internet technologies, oriented to the field of "intelligent" objects (machines and products), there is a new paradigm shift in industrial production, characterized by modular manufacturing systems and scenarios in which products control their own manufacturing process - performing the manufacturing of individual products in a single batch size - bringing the term "industry 4.0" to the level of a "fourth industrial revolution" (Sanders et al., 2016).

The term Industry 4.0, or "Industrie 4.0", in German, appeared in 2011 at a trade show in the city of Hannover, Germany (Sanders et al., 2016). Industry technologies 4.0, smart manufacturing, smart products, big data (BD), and the Internet of Things (loT), among others, are some of the topics of digital and automated manufacturing (Kamble et al., 2018). Industry 4.0 approaches combine the interface of knowledge areas of electrical engineering, business administration, computer science, business systems and information engineering and mechanical engineering, as well as areas of complementary knowledge (Lasi et al., 2014). 
With the emergence of new methods and production systems, there is no doubt about the need for a new concept of quality, which includes personalized services and a focus on product design (Park, 1995). Beginning with mass production, characterized by low diversity and large quantities of products, several methods for quality management, analysis and monitoring were employed (Ngo \& Schmitt, 2016). As a consequence, quality management (QM) became popular in the 1980s and 1990s, but companies in the 21st century, in the era of Industry 4.0 are still struggling with its application (Gunasekaran et al., 2019).

In this way, quality engineering has been following the transformations promoted by emerging technologies within organizations, as highlighted by Miller et al. (2018), where decisions with a focus on quality on the organizational level can be seen as one of the significant features of a strategic plan. These quality challenges raise questions about where we are on the quality journey and to what extent traditional quality management practices and methods have absorbed changes in the stages of product development in Industry 4.0 (Gunasekaran et al., 2019). Therefore, Ngo \& Schmitt (2016) emphasize that quality management along the value chain is becoming increasingly complex, and Telukdarie et al. (2018) suggest that the integration of centralized functions by Industry 4.0 should offer significant business value, providing strategic and operational benefits.

For this integration to occur, big data is one of the recent technological advances with strong applicability in almost all sectors, including manufacturing. However, despite the business opportunities offered by this technology, its adoption is still at an early stage in many industries (Yadegaridehkordi et al., 2018). Kampker et al. (2018) emphasize that current production environments and automated data acquisition are hampered by heterogeneous databases with limited access, lack of trace information and reduced information sets due to lack of time-series data and high costs for new infrastructure. These issues further hinder the application of data analysis methods.

Gunasekaran et al. (2019) presented a systematic review of articles addressing quality in the era of Industry 4.0. The authors presented several research gaps and categorized studies. In this paper, through a systematic review of the literature, we found seventeen papers that addressed gaps highlighted by their previous review. In addition, we addressed the concepts of big data and Industry 4.0 for decision-making regarding quality control. Our results show that the problems highlighted by Gunasekaran et al. (2019) are not entirely resolved and suggest new directions of research. Finally, our study contributes to the continued consolidation of the Industry 4.0 and quality management concepts.

The article is structured as follows. Section 2 presents the method adopted in this study. Section 3 provides the theoretical framework for the classification of Industry 4.0 in decision-making (DM) and quality management (QM). Finally, section 4 presents the results obtained and directions for future research.

\section{Methods}

The methods of this research can be divided into three essential phases: research definitions, methods of data collection, and analysis of results, according to Figure 1.

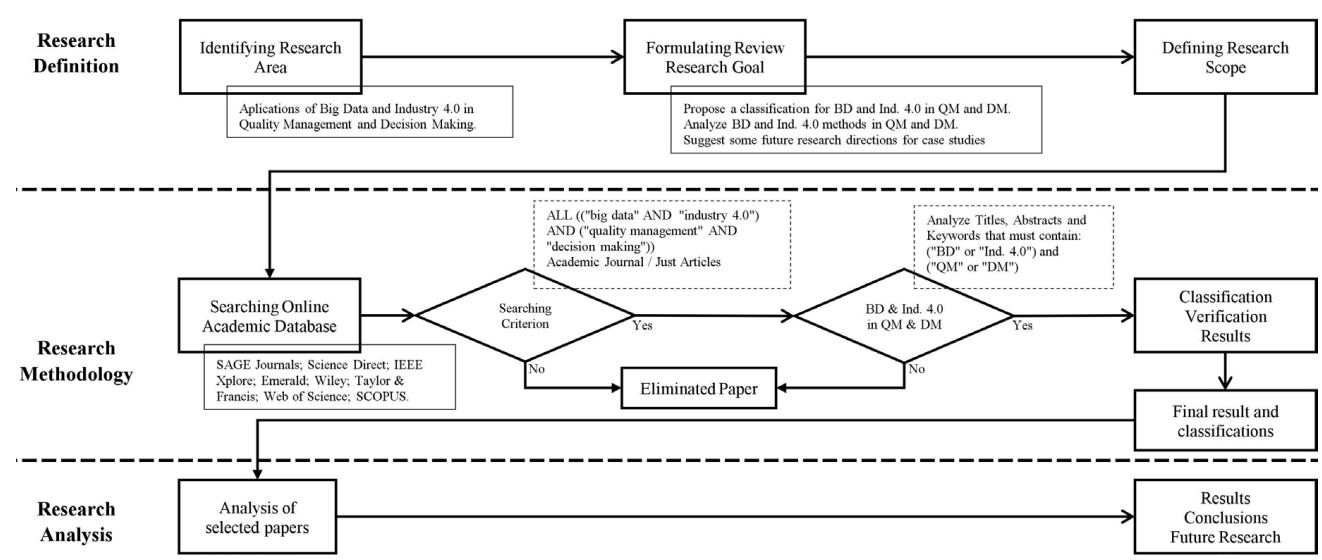

Figure 1. Methodological framework for research.

In phase 1 , we determine the research area, the objective, and the scope. The research area is a systematic review of decision-making (DM) and quality management (QM) methods in Industry 4.0 (Ind 4.0) and big data $(\mathrm{BD})$. In the research objective, we identified the evolution of quality control decision-making in Industry 
4.0 and verified how big data impacts quality control. As the research on this subject is relatively recent, the scope of this investigation was not limited to a specific period.

In phase 2, we defined rules for the search for a selection of articles and created tables for the classification of these articles. The SCOPUS and Web of Science databases as well as other databases, such as SAGE Journals, Science Direct, IEEE Xplore, Emerald, Wiley, Google Scholar and Taylor \& Francis, were included to obtain the greatest number of relevant papers. This bibliographic search was based on the search term "ALl (("big data" AND "industry 4.0") AND (“quality management" AND "decision making”))". We used these terms to search the online databases, which resulted in 119 articles. The review and classification processes were carried out jointly by the two authors, selecting only articles related to $\mathrm{BD} / \mathrm{lnd} 4.0$ and $\mathrm{QM} / \mathrm{DM}$. The articles selected must have been published in scholarly journals, and full-text versions must be available. Conference papers, master's or doctorate dissertations, textbooks, and unpublished working papers were excluded. Finally, when reading the titles, abstracts and keywords, the final selection was related to articles that presented approaches to BD/Ind 4.0 and QM/DM.

In the last phase, we analyzed the selected articles to structure the classification according to the method proposed by Gunasekaran et al. (2019). We ranked the selected articles according to the research potential in the Industry 4.0 era (Table 1) and categorized the surveys according to the relation between human aspects and technological changes in the industry (Table 2). Finally, 11 research questions presented by Gunasekaran et al. (2019) were considered to analyze the selected studies (Table 3).

Table 1. Classification method.

\begin{tabular}{|c|c|}
\hline Item & Definition \\
\hline \multirow[t]{3}{*}{1} & The basic role that quality plays in the economic performance of companies; \\
\hline & New performance measures and metrics for peer-driven target settings and customer expectations; \\
\hline & Sophistication in quality standards, practices and methods to gain sustainable competitive advantage. \\
\hline \multirow[t]{2}{*}{2} & Decision models related to contemporary quality management; \\
\hline & Costs of poor-quality decision models in terms of customer expectations and credibility. \\
\hline \multirow[t]{5}{*}{3} & Contemporary lean techniques and economic influences in manufacturing and services; \\
\hline & Outsourcing/offshoring quality challenges in logistics and supply chain operations in the era of Industry 4.0 ; \\
\hline & Continuous improvement strategies and models that result in minimal viable change and pivoting; \\
\hline & Emerging philosophies and business tactics that look beyond total quality management and six sigma; \\
\hline & The role of product innovation, design (R\&D) and grassroots autonomy in quality management. \\
\hline \multirow[t]{4}{*}{4} & Capturing message credibility and supplier involvement aspects in qualify function deployment; \\
\hline & Leadership emphasis and process flexibility in achieving economic sustainability; \\
\hline & Business models and tactics for peer involvement of employees within enterprises; \\
\hline & Business models that study the influence of quality management in a multicultural environment. \\
\hline 5 & The role of technology, automation and IT/IS in quality management and its relationship with employee empowerment. \\
\hline
\end{tabular}

Source: Gunasekaran et al. (2019).

Table 2. Categorization method for the alignment between human aspects and evolution of technologies.

\begin{tabular}{|c|c|}
\hline Item & Definition \\
\hline \multirow[t]{3}{*}{6} & The economic aspects include the basic role that quality plays in the economic performance of companies; \\
\hline & Aspects of decision models including the costs of poor-quality decision models in terms of customer expectations and credibility; \\
\hline & $\begin{array}{l}\text { Aspects of business models regarding the continuous improvement strategies and models that result in minimal viable change and } \\
\text { pivoting. }\end{array}$ \\
\hline \multirow[t]{3}{*}{7} & $\begin{array}{l}\text { Human aspects include i) leadership emphasis and process flexibility in achieving economic sustainability and ii) business model and } \\
\text { tactics for peer involvement of employees within enterprises and capturing messages. Credibility and supplier involvement in qualify } \\
\text { function deployment; }\end{array}$ \\
\hline & Decision model aspects include decision models related to contemporary quality management; \\
\hline & $\begin{array}{l}\text { Business model aspects include: i) contemporary lean techniques and economic influences in manufacturing and services and ii) emerging } \\
\text { philosophies and business tactics that look beyond total quality management and six sigma. }\end{array}$ \\
\hline \multirow[t]{2}{*}{8} & $\begin{array}{l}\text { Economic aspects include: i) new performance measures and metrics for peer-driven target settings and customer expectations and ii) } \\
\text { sophistication in quality standards, practices and methods to gain sustainable competitive advantage; }\end{array}$ \\
\hline & $\begin{array}{l}\text { Business model aspects include: i) outsourcing/offshoring quality challenges in logistics and supply chain operations in the era of lndustry } \\
4.0 \text { and ii) the role of product innovation, design (R\&D) and grassroots autonomy in quality management. }\end{array}$ \\
\hline 9 & $\begin{array}{l}\text { Technological aspect: the role of technology, automation and IT/1S in quality management and its relationship with employee } \\
\text { empowerment. }\end{array}$ \\
\hline
\end{tabular}

Source: Gunasekaran et al. (2019). 
Table 3. Research questions.

\begin{tabular}{cl}
\hline Item & \multicolumn{1}{c}{ Definition } \\
\hline 1 & $\begin{array}{l}\text { What changes need to be made in quality management to commit to micro level human involvement with respect to emerging new } \\
\text { technologies, such as blockchain, the Internet of Things, big data, business analytics, cyber physical systems and smart supply chains? }\end{array}$ \\
2 & What are the new quality-related performance measures and metrics for the futuristic supply chains? \\
3 & What sophisticated methods have been developed to capture new emerging quality challenges, such as quality risk, security, trust and \\
& compliance?
\end{tabular}

Source: Gunasekaran et al. (2019).

\section{Industry 4.0 and quality}

For Industry 4.0, almost every workflow depends on high-quality data and accurate information. Therefore, these aspects are becoming a primary component of a thriving industrial system (Li et al., 2015).

\subsection{Summary of selected studies}

The articles were collected on May 9, 2019. We obtained 12 articles on Emerald, 4 in SAGE Journals, 53 in ScienceDirect and 50 in SCOPUS. However, at IEEE Xplore, Wiley, Taylor \& Francis and Web of Science, we did not find results for our research area. Therefore, we applied the exclusion criteria to 119 articles, considering the analysis of titles, abstracts, and keywords. The results were imported into JabRef to exclude the articles that referred to conferences and book chapters since the focus of the research was journals with a high impact factor. After excluding conference papers, 116 articles were left, and after excluding book chapters, 99 articles were left. Finally, duplicate articles were deleted, and 96 were left. After applying the exclusion criteria following the reading of titles, abstracts and keywords (which should contain the terms big data OR Industry 4.0 and quality management OR decision-making), we obtained 19 articles for a detailed reading. Of the 19 resulting articles, two were excluded following a detailed reading because they did not align with the theme of quality management in Industry 4.0 (Raut et al., 2019; Tsai et al., 2019a); this finally yielded 17 articles for classification. We also analyzed the development of the 17 selected articles. These data are presented in Table 4.

Table 4. Studies selected in ("BD” or "Ind. 4.0") and ("QM" or "DM").

\begin{tabular}{lcc}
\hline \multicolumn{1}{c}{ Author } & Area & Country \\
\hline Ngo \& Schmitt (2016) & Academic & Germany \\
D’Emilia et al. (2018) & Manufacture & ltaly \\
Ding (2018) & Pharma Industry & UK \\
lrani et al. (2018) & Food Industry & UK \\
Kampker et al. (2018) & Manufacture & Germany \\
Kozjek et al. (2018) & Auto Industry & Slovenia \\
Lin et al. (2018) & Auto Industry & China \\
Melnyk et al. (2018) & Supply Chain & Australia \\
Müller et al. (2018) & Germany SME; & Germany \\
Telukdarie et al. (2018) & Supply Chain & China \\
Tsai \& Lai (2018) & Sustainability & China \\
Yadegaridehkordi et al. (2018) & Manufacture & Malaysia \\
Nascimento et al. (2019) & Academic & Argentina \\
Para et al. (2019) & Auto Industry & Spain \\
Ren et al. (2019) & Sustainability & China \\
Rossit et al. (2019) & Supply Chain & Brazil \\
Tsai et al. (2019b) & Sustainability & Taiwan \\
\hline
\end{tabular}


Of the 119 articles collected, interestingly, we did not find any study that was related to the results of Gunasekaran et al. (2019). However, we identified an article that presents a summary of these papers, which we used to classify our results about Industry 4.0 and quality management. Most of the selected studies address the quality business models in the lndustry 4.0 era. In terms of methodologies, this study presented empirical articles that range from mathematical models to conceptual and simulation models, with appropriate case studies or large-scale research. In the next subsection, we present a summary of the central studies.

The monitoring of quality in customized production is becoming increasingly sophisticated; thus, the article by Ngo \& Schmitt (2016) describes an approach based on a virtual production model to validate the data mining methods suitable for quality assurance. This procedure develops a virtual productive process, whose results provide the data necessary for the data mining method to be validated. Thus, for the regulation of data quality, four fields of action were presented, corresponding to the research needs: (1) identification of quality-relevant data and data sources; (2) development of an IT architecture; (3) application of data mining methods for analysis and prediction of quality progressions; and (4) derivation of measures for quality regulation. These fields of action are intended to deliver a framework for quality in Industry 4.0.

The Irani et al. (2018) article provides a perspective of the organizational factors to be managed, contributing to the reduction of food waste through the principles of design science and exploring the causal relationships between the factors of consumption distributions. Cause and effect models constructed and "what-if" simulations are conducted for the development and implementation of a fuzzy cognitive map (FCM). This study serves as evidence to support the development of policies that facilitate interventions to reduce food losses against the backdrop of a major framework proposal for food security.

Kampker et al. (2018) used the data-use-case-matrix (DUCM) for data analysis during the early stages of technological development. Therefore, the approach presented focused on three ideas: i) the availability of adaptive data; ii) strategic prioritization; and (iii) scalable data analysis. Through the example of an automotive manufacturing application, a first glimpse of the possible benefits of this method was proven. Using the adaptive data availability method, the authors constructed a DUCM for high-voltage batteries, allowing the strategic prioritization of the identified use cases and, consequently, the selection of the decision support use case. Through an example of the application of the automotive manufacturing domain, a first glimpse of the possible benefits of this method was provided.

According to Kozjek et al. (2018), manufacturing data provide excellent potential to improve the management of manufacturing operations. In this way, the authors use an approach for the analysis of data in technical systems for manufacturing, engineer to order (ETO), in which the quality of the product and the reliability of the delivery date play a fundamental role in management decision-making. The objective of the study was to investigate manufacturing data collected by a manufacturing execution system (MES) during operations at an ETO company and develop tools to support operations planning. The developed tools can be used for production simulation and the prediction of potential resource overloads. Using big data analytics, the results presented by the authors demonstrate that this type of analysis can help better manage operations, improve resource utilization, and give decision-makers better reliability. The article also demonstrates the control structure used for the management of the autonomous system.

The search of Telukdarie et al. (2018) proposes a global approach to the Industry 4.0 system (vertical, horizontal, and total business integration) through manufacturing systems to instrumentation via ERP. Substantially, a business solution that is fully integrated and able to handle relevant data facilitates near-real-time decision-making, which is a weakness in current systems. The proposed paper solves the challenges with global standardization and cross-functional integration. A simulation that illustrates the benefits of integrated business reinforces this proposed architecture. The framework presented by the authors demonstrates which main tools are used for the full integration of the business system, such as security services and cloud services, to facilitate decision-making.

The objective of Tsai \& Lai (2018) was to create a mathematical programming decision model that integrates green manufacturing technologies, costing based on activity (ABC) and the theory of constraints (TOC). This model should assist in the preparation of production plans and optimize the selection of the best and most profitable product mix. In addition, this study proposes that technologies developed by lndustry 4.0 applied to production control can increase efficiency and quality. The results of this study contribute to improving the competitiveness of the paper industry and provide insights into the value of applying an integrated mathematical programming model to product mix decision-making. Moreover, the authors apply Industry 4.0 technologies to machine maintenance and quality control in manufacturing workshops.

The study of Yadegaridehkordi et al. (2018) aimed to identify and classify the factors that influence the adoption of big data and, in turn, to predict its influence on the performance of manufacturing companies using a hybrid approach involving the decision-making trial and evaluation laboratory (DEMATEL) and adaptive 
neuro-fuzzy inference systems (ANFIS). The study identified critical adoption factors from a literature review and categorized them into technological, organizational, and environmental dimensions. Data were collected from 234 industrial managers who were involved in the decision-making process regarding IT acquisition in manufacturing companies in Malaysia. The results of the study showed that technological factors have the most considerable influence on the adoption of big data and the performance of companies. The study shows that complexity and technological resources for adoption are the main barriers to adopting technological factors.

The study of Para et al. (2019) presents the methodology Analyze, Sense, Preprocess, Predict, Implement, and Deploy (ASPPID), an interactive decision flow to improve the production stage. By putting the data analyst at the center of the workflow, this methodology helps improvement teams make decisions about what parts of a process need to be investigated and how to exploit that information for verifiable improvement in the production cycle. The methodology implementation is exemplified by a real case study of the automotive industry, where the detection of defects in an annealing process can be modeled as a classification problem in a highly unbalanced data set. The results obtained after applying the ASPPID methodology showed that the scrap rate was reduced, thus highlighting the crucial role of the data analyst in the plant management team.

In the study developed by Tsai et al. (2019b), the authors present a structure for the study of the relationship between the manufacturing execution system (MES) and activity-based standard costing (ABSC). These results demonstrate the concept of $\mathrm{ABSC}$, combining activity-based costing $(\mathrm{ABC})$ and MES. Finally, the authors describe the ABSC mixed decision model using mathematical programming (with LINGO software). With limited resources, the optimal solution and the ideal profit are obtained. $A B C$ implementation can meet the cost information needs of a company's managers. However, ABSC can be a cost-effective tool to improve operational skills in terms of quality, cost, delivery, service, features and productivity in a modern and intelligent factory that uses high-technology uncrewed vehicles, advanced robots, and various sensors, among others. A roadmap was presented to operationalize a smart ABSC, as well as other frameworks integrating MES and ABSC.

\subsection{Analysis of results}

Table 4 presents the classification of the study areas found in the articles, where the area of sustainability is the most approached topic.

Most of the articles about big data OR Industry 4.0 AND quality management OR decision-making are from in China, Table 4. Additionally, related surveys are from China for reasons including government policy, as the country is undergoing a plan called Made in China 2025, which includes support for the development of advanced manufacturing. Innovation as a strategy to achieve economic and social development ensures that Chinese scientific production, among other vital aspects, is among the most cited in the world to boost research in various areas (Li, 2018). For small and medium-sized automotive industries, we can highlight Germany, which is the second country in terms of publications on this topic as well as the pioneer country in the development of Industry 4.0 (Almada-Lobo, 2016).

The classification of the topics of quality management in Industry 4.0, presented in Table 5, was structured according to Tables 1 to 3 .

Table 5 maps the articles concerning human involvement in the quality and technology revolution. For classification, the researchers used the following definitions: high individual involvement and high use of recent technology were characterized as microlevel engagement. For example, microlevel engagement concerned human involvement in dealing with radical aspects of risk, management security, and the alignment of quality management systems for new technologies, such as blockchain, loT, BD, and CBS. In contrast, macro-level engagements were considered issues of continuous improvement and technological revolution. The results show that human intervention and programming are still necessary for technology to have a high level of practicality. In the same way, it is possible to observe that technologies and human involvement are rarely used, represented by macrolevel engagement.

The last analysis presented in this study involves the categorization of gaps suggested in Gunasekaran et al. (2019). The authors suggested research questions to be addressed, not all of which were considered in later studies (Table 5). That is, there are still gaps to be addressed regarding quality management in Industry 4.0. The gaps suggested by Gunasekaran et al. (2019) address issues such as quality management and human involvement, new performance metrics in quality management, and outsourcing services, among other aspects involving the future of quality management in companies. The research questions can be found in the article that summarizes the results of this study. Thus, the articles collected in this study were classified according to which research gap they addressed. 
Table 5. Classification of studies.

\begin{tabular}{|c|c|c|c|c|c|c|c|c|c|c|c|c|c|c|c|c|c|c|c|c|}
\hline \multirow{2}{*}{ Author } & \multicolumn{9}{|c|}{ Classification } & \multicolumn{11}{|c|}{ Questions } \\
\hline & 1 & 2 & 3 & 4 & 5 & 6 & 7 & 8 & 9 & 1 & 2 & 3 & 4 & 5 & 6 & 7 & 8 & 9 & 10 & 11 \\
\hline Ngo \& Schmitt (2016) & & & & & $\mathrm{x}$ & & & $\mathrm{x}$ & & & & & & & $\mathrm{x}$ & & & & & \\
\hline D’Emilia et al. (2018) & & & & & $\mathrm{x}$ & & $\mathrm{x}$ & & & & & & & $\mathrm{x}$ & & & & & & \\
\hline Ding (2018) & & & $\mathrm{x}$ & & & & $\mathrm{x}$ & & & & & & & & $\mathrm{x}$ & & & & & \\
\hline Irani et al. (2018) & & $\mathrm{x}$ & & & & & & & $\mathrm{x}$ & & & $\mathrm{x}$ & & & & $\mathrm{x}$ & & & & \\
\hline Kampker et al. (2018) & & & & & $\mathrm{x}$ & & $x$ & & & & & & & $\mathrm{x}$ & & & & & & \\
\hline Kozjek et al. (2018) & & $\mathrm{x}$ & & & & & & $\mathrm{x}$ & & & & & & & $\mathrm{x}$ & & $\mathrm{x}$ & & & \\
\hline Lin et al. (2018) & & & $\mathrm{x}$ & & & & $\mathrm{x}$ & & & $\mathrm{x}$ & & & & $\mathrm{x}$ & & & & & & \\
\hline Melnyk et al. (2018) & & & & & $\mathrm{x}$ & $\mathrm{x}$ & & & & & & & & & & & & & & \\
\hline Müller et al. (2018) & & & $\mathrm{x}$ & & & $\mathrm{x}$ & & & & & & & & & & & & & & \\
\hline Telukdarie et al. (2018) & & & $\mathrm{x}$ & & & & $x$ & & & & $\mathrm{x}$ & & & & & & & & $\mathrm{x}$ & \\
\hline Tsai \& Lai (2018) & & $\mathrm{x}$ & & & & & & & $x$ & & & $\mathrm{x}$ & & $\mathrm{x}$ & $\mathrm{x}$ & $\mathrm{x}$ & & & & \\
\hline Yadegaridehkordi et al. (2018) & & $\mathrm{x}$ & & & & & & & $\mathrm{x}$ & & & $\mathrm{x}$ & & & & & & & & \\
\hline Nascimento et al. (2019) & & & & & $\mathrm{x}$ & & $\mathrm{x}$ & & & & $\mathrm{x}$ & & & & & & & & & \\
\hline Para et al. (2019) & & $\mathrm{x}$ & & & & & & & $x$ & & & $\mathrm{x}$ & & & & & & & & \\
\hline Ren et al. (2019) & & & & & $\mathrm{x}$ & & & $\mathrm{x}$ & & & & & & $\mathrm{x}$ & $\mathrm{x}$ & $\mathrm{x}$ & $\mathrm{x}$ & & & \\
\hline Rossit et al. (2019) & & $x$ & & & & & & $\mathrm{x}$ & & & & $\mathrm{x}$ & & & $x$ & & & & & \\
\hline Tsai et al. (2019b) & $\mathrm{x}$ & & & & & & & & $x$ & & & $\mathrm{x}$ & & & & $\mathrm{x}$ & & & & \\
\hline
\end{tabular}

Regarding Table 5, Tsai et al. (2019b) implement an ABC approach to customer needs with cost information for the customer, thus providing a more cost-effective approach to Industry 4.0; therefore, this study addresses an economic aspect of quality in the era of Industry 4.0. Regarding the classification of the models of decision-making regarding quality in the era of Industry 4.0, Yadegaridehkordi et al. (2018), for example, pioneered the development of software for decision-making in industries, while Kozjek et al. (2018) present a pilot study in an automotive industry using the manufacturing execution system to support decision-making in operations management. The studies of Telukdarie et al. (2018) and Ding (2018) consider quality business models in the era of Industry 4.0; the first study proposes a method to manage and automate global business through optimization in a single system, while the second study identifies potential barriers in business and sustainable relationships whose identification could improve a company's management system, focusing on pharmaceuticals. Finally, Kampker et al. (2018) apply various analytical methods and data combinations to investigate strategic prioritization and decision-making support; their article is different from other studies regarding decision-making since it presents technological aspects of quality in the era of Industry 4.0 because of technological bias in 1T/1S.

The articles of Ngo \& Schmitt (2016), Ren et al. (2019), Kozjek et al. (2018) and Rossit et al. (2019) considered issues with high technological demand (CBS, loT, BD) but low human involvement and were classified as studies focusing on micro technology and macro human involvement. Due to the high human and technological involvement, the studies of Tsai \& Lai (2018) and Para et al. (2019) were classified as addressing microlevel engagement. Tsai \& Lai (2018) developed mathematical programming with TOC tools and ABC to prepare and make decisions regarding the production plan for a broad mix of products. Para et al. (2019) performed, through $\mathrm{Al}$, the detection of defects in an annealing process, remodeling the programming to correct unbalanced production. Yadegaridehkordi et al. (2018) and lrani et al. (2018) were also classified as addressing microlevel engagement because they used computational simulation methodologies to aid decision-making in companies. The article developed by Melnyk et al. (2018), who approached and dealt with tools of low technological level, was classified as addressing macrolevel engagement. In the same group, Müller et al. (2018) also used mechanisms of low technological complexity and human involvement. Finally, regarding the classification of macro technology and micro human involvement, D'Emilia et al. (2018), Lin et al. (2018), Telukdarie et al. (2018), Ding (2018), Kampker et al. (2018) and Nascimento et al. (2019), show in their research models that the execution of decision-making in a business requires high human involvement to ensure the ability to elaborate a technology, as long as it is not emergent; thus, their studies differed from articles classified as high involvement in both aspects.

The research gaps were filled according to the objective and the result of the articles and, in other words, how the articles responded to each question. For example, lin et al. (2018) provide insights into Industry 4.0 by examining key factors of advanced technology and quality management in the automotive industry. In this 
way, this article helps answer two questions ( 1 and 5) about the changes companies need to make for quality management in Industry 4.0 and the incentive for autonomous quality management.

Telukdarie et al. (2018) and Nascimento et al. (2019) help define the new quality and supply chain performance metrics in question 2. However, only the first article tells how to conduct quality trading with the support of sophisticated supply chain methods. The contribution of this article is the proposed method to manage and automate/optimize global business through a single conglomerate of cyber-physical systems.

Several selected articles address the development of sophisticated methods for handling emerging quality challenges, such as quality, safety, trust, and compliance risk, which is the third research gap suggested by the author. Among them, we can highlight lrani et al. (2018) and Yadegaridehkordi et al. (2018), who use simulation methods for decision-making and introduce a variable for the issue of risk associated with such decision-making.

Studies such as those of Tsai \& Lai (2018) and Kozjek et al. (2018) are related to the sixth gap indicated by the article, concerning the development of contemporary lean techniques in the current industrial revolution. Both use simulation tools for analysis and decision-making. The first study presents a new philosophy of total quality, which concerns the sustainability bias in the decision models (and thus also answers the seventh question). The second article brings the aspect of leadership and agility into processes to achieve economic sustainability in the era of Industry 4.0 (which also responds to the eighth research gap).

None of the articles reviewed in this study were able to answer questions 4 , 9, and 11 suggested by Gunasekaran et al. (2019), indicating the remaining gaps for further research. Therefore, no article attempted to address service outsourcing, the involvement of employees to meet quality standards, the decision modeling process concerning low quality, or customer expectations and credibility that fit future supply chains in Industry 4.0.

Considering that most of the research questions (Table 3) have already been addressed in the literature, we suggested issues for future research in terms of quality management and Industry 4.0. In this way, we elaborated Table 6, which presents suggestions evidenced from the 17 articles selected for this study, classified by author, and provides a framework of the gaps to be explored.

Table 6. Suggested future research directions.

\begin{tabular}{|c|c|}
\hline Author & Future research \\
\hline Tsai et al. (2019b) & $\begin{array}{l}\text { They suggest that ABSC be used to integrate internal and external systems into the MES to connect all the } \\
\text { real-time information about relevant requirements that will help all industries in the digital age. }\end{array}$ \\
\hline Para et al. (2019) & $\begin{array}{l}\text { They recommend the inclusion and hybridization of existing production models for data mining } \\
\text { (e.g., CRISPDM) and the development of agile software (SCRUM or lean software, among others) within the } \\
\text { ASPPID methodology, with a particular emphasis on learning how to incorporate multiple criteria of conflicting } \\
\text { decisions for decision-making in the production process. }\end{array}$ \\
\hline Nascimento et al. (2019) & $\begin{array}{l}\text { Limitations of the research refer to the perceptions of the participants in the focus groups, which introduces } \\
\text { subjectivity, and the small sample of specialists considered, which does not allow generalization of the results. } \\
\text { Therefore, it is suggested to focus on these two areas. }\end{array}$ \\
\hline Yadegaridehkordi et al. (2018) & $\begin{array}{l}\text { Future studies may consider other MCDM techniques, such as TOPSIS and ANP, combined with soft computing } \\
\text { techniques to produce more interesting results or even to compare the results of different techniques. }\end{array}$ \\
\hline Lin et al. (2018) & $\begin{array}{l}\text { Comparative studies can be conducted to investigate different responses to Industry } 4.0 \text { technologies in } \\
\text { automotive industries across countries. }\end{array}$ \\
\hline Telukdarie et al. (2018) & $\begin{array}{l}\text { Future studies may develop advanced data analysis algorithms focused on industry-specific combinations of } \\
\text { business and Industry 4.0, which can be applied globally. }\end{array}$ \\
\hline Kozjek et al. (2018) & $\begin{array}{l}\text { The authors identified challenges in the development and implementation of analytical data tools in real } \\
\text { manufacturing environments. }\end{array}$ \\
\hline Kampker et al. (2018) & $\begin{array}{l}\text { Future research may focus on harnessing the full potential of manufacturing data and extending the concepts } \\
\text { of adaptive availability of these to provide a more significant knowledge base. }\end{array}$ \\
\hline Irani et al. (2018) & They suggest other authors to design and build big data research in food supply chains. \\
\hline Tsai \& Lai (2018) & $\begin{array}{l}\text { When planning their profit targets, companies should also consider the multi-objective considerations of } \\
\text { customer service levels and supplier profits. }\end{array}$ \\
\hline Ngo \& Schmitt (2016) & $\begin{array}{l}\text { To conduct quality regulation, based on data in practice, further research is needed in four fields of action: } \\
\text { (1) identification of quality-relevant data and data sources, (2) development of an IT-architecture, (3) } \\
\text { application of data mining methods for analyzing and prediction of quality progressions, and (4) derivation of } \\
\text { measures for quality regulation. }\end{array}$ \\
\hline
\end{tabular}

In the study by Tsai et al. (2019b), the authors suggest activity-based standard costing (ABSC) as a costing tool for improving business operational skills regarding quality, cost, delivery, service, resources, and productivity in an intelligent factory. In addition, they suggest that ABSC be used to integrate internal and external systems with the manufacturing execution system (MES) to connect real-time information on relevant requirements, which could help all industries in the digital age. Additionally, in terms of resources, Tsai \& Lai (2018) suggest 
using $\mathrm{ABC}$ resources to identify costly resources and inefficient processes or activities and then enhance them using various methods (including Industry 4.0 related technologies). In this regard, future research may consider whether when planning their profit targets, companies must also take into account the multi-objective considerations of customer service levels and supplier profits.

A real case study was used to validate the study by Para et al. (2019), in which a reduction in costs (above 43\%) was achieved with the use of sensors, achieving a non-quality rate (NQR) lower than the target value imposed at the beginning of ASPPID (Analyze, Sense, Preprocess, Predict, Implement, and Deploy). Thus, to improve the results obtained, the authors recommend the hybridization of existing production models for data mining and the development of agile software in the ASPPID methodology. They emphasize the importance of understanding how to incorporate multiple criteria for conflicting decision-making into the production process.

Nascimento et al. (2019) demonstrated limitations regarding the subjectivity and generalization of their results. Subjectivity was introduced through the perceptions of participants in the focus groups, and the difficulty in generalizing the results was due to the limited number of experts. Therefore, the authors suggested deeper research on emerging technologies from Industry 4.0 and how they can be integrated with circular economy (CE) practices to establish a business model that reuses and recycles waste materials.

Regarding the factors that influence the adoption of big data, Yadegaridehkordi et al. (2018) highlighted that technological factors exert more significant influence than organizational and environmental factors. Future studies may consider other MCDM techniques (such as TOPSIS and ANP) combined with soft computing techniques. New techniques may produce new results, and a comparison of methods is recommended. These results can help improve the performance of companies that decide to adopt big data.

Lin et al. (2018) developed a study on the applicability of Industry 4.0 technologies to the Chinese automotive industry, called "Made in China 2025". The results showed that the factor "company size and nature" does not increase the use of advanced production technologies. In addition, the impacts of factors such as "IT maturity" and "technological incentive" are more significant than the impacts of "external pressure" and "government policy". In this regard, comparative studies are recommended to investigate different responses to Industry 4.0 technologies in the automotive industries of other countries.

Telukdarie et al. (2018) propose a global system approach as defined by Industry 4.0 (vertical, horizontal, and total business integration). This research presents the ability to develop a single global solution as a standard. Consequently, the authors suggest the development of advanced algorithms for data analysis centered on lndustry 4.0 opportunities in businesses and countries that referenced globally.

The research by Kozjek et al. (2018) addresses data analysis in engineer-to-order (ET0) manufacturing systems, where product quality and due date reliability play a key role in management decision-making. In this way, the authors identified challenges in the development and implementation of analytical data tools in real manufacturing environments. As a result, some of the challenges for future research concern the consideration of other observed production specificities (for example, the completion of some work orders may be a prerequisite for starting another, and joining similar operations may reduce system setup time) and the development of methods that provide accurate and reliable estimates.

Kampker et al. (2018) presented an adaptive approach to data analysis in electric car manufacturing. The approach focuses on adapting to data availability. This method can even be implemented in the early stages of prototype development. In this sense, future research should focus on exploring the full potential of the core ideas identified for data analysis in manufacturing. These concepts need to be extended to provide a broader knowledge base.

The article by Irani et al. (2018) provides a managerial perspective on the organizational factors that contribute to reducing food waste. The findings support policymakers in developing policies that facilitate interventions to reduce food losses. To extend these findings, the authors suggest using big data in food supply chains.

Ngo \& Schmitt's (2016) article describes quality regulation based on data mining. To conduct quality regulation based on real data, further research is needed in four fields of action: (1) identification of quality-relevant data and data sources, (2) development of an IT architecture, (3) application of data mining methods for analyzing and prediction of quality progressions, and (4) derivation of measures for quality regulation.

\subsection{Discussion}

Given the results obtained, the article presents the evolution of an emerging research topic. Of the 17 articles collected, 11 are from 2018 and 5 are from 2019, and all investigate the benefits and limitations of decision-making and quality management in Industry 4.0. A point of discussion refers to the fact that we did 
not find the studies considered by Gunasekaran et al. (2019), which shows that the research keywords chosen by the authors presented complementary results.

The techniques and areas studied also indicate increasingly diverse results in different parts of the world. The results of this systematic review, although subjective in classification, are promising for the future, leading us to believe that in a short time, it will be feasible to use this technology in other parts of the world. A similar observation found in the articles regarding the trends of future research refers to the suggestion for the continuous improvement of the tools the authors developed, indicating that many of the decision models developed have further capacities to be explored. The diversity of areas that were observed and discussed in this article also leads us to believe that there will be an expansion of these techniques to various areas of knowledge. The majority of the studies still focus on industry and manufacturing. However, it is already possible to find studies seeking tools and techniques for Industry 4.0 to help in decision-making in the areas of pharmaceuticals, food, and sustainability.

This study shows that in the period of the considered articles' publication, several research gaps suggested previously were filled, indicating that other researchers have continued to study the subject. Building on this knowledge and benefitting from government incentives and the reduced cost of implementing such technologies, new related studies may fill many of the remaining gaps. Additionally, most of the applications presented in the articles studied provide technological gains for companies; that is, they present financial and sustainability gains. These benefits will drive an increasing number of companies to invest in and improve their processes using the related tools.

Despite promising results, as mentioned above, certain gaps have not been satisfactorily fulfilled in this article. We cite the need for study of the outsourcing of services in Industry 4.0, which is an emerging theme that has yet been little explored in some parts of the world concerning the gains a company may achieve by pioneering in outsourcing with Industry 4.0. Another point of inquiry concerns the study of customer expectations and credibility suitable for the supply chain of the future, an issue that is relevant because it concerns the most critical asset of the company, the customer.

\section{Final remarks and future research}

This study contributes to the literature regarding decision-making and quality management in Industry 4.0 through identifying the evolution of related concepts, presenting various indicators and organizing the data about the subjects researched. The literature review revealed that several authors address new trends in decision-making and quality control, as well as Industry 4.0. Knowledge and organizations can help industry managers make business decisions with more understanding and knowledge of new tools for application. Researchers can also use the review to consider gaps not yet addressed at the time of this article's publication.

This study also contributes to Gunasekaran et al. (2019) because the majority of the research gaps presented by the authors, resulting in a call for papers that were published in early 2019 , have already been answered. We present new gaps to be filled and categorized according to the criteria established in the method for analysis of the 17 articles selected for review. We therefore contribute to continued research in quality management and Industry 4.0.

We believe that the systematic review carried out yields new expectations about decision-making and quality management concerning lndustry 4.0. Some gaps, as mentioned in the previous section, remain concerning this new period of industry, for example, outsourcing, customer expectations, and employee involvement in new quality standards. However, we envisage a vast field of possibilities for research and exploration of topics related to technology and quality management in Industry 4.0, especially considering the current global situation.

For future studies, we suggest continued research on decision-making and data analysis in Industry 4.0. Authors such as Para et al. (2019) and Yadegaridehkordi et al. (2018) suggest the refinement of their methods for decision-making in this new industrial context. Referring to data analysis, Para et al. (2019), Telukdarie et al. (2018), Kozjek et al. (2018), Kampker et al. (2018), Irani et al. (2018) and Ngo \& Schmitt (2016) highlight the importance of continued studies related to data mining, big data, and data analytics. Additionally, Lin et al. (2018) emphasize the importance of comparing the use of industry technologies across countries.

\section{Acknowledgements}

Authors thanks CAPES (Coordenação de Aperfeiçoamento de Pessoal de Nível Superior) for supporting this research - Process 88887.342073/2019-00. 


\section{References}

Almada-Lobo, F. (2016). The industry 4.0 revolution and the future of manufacturing execution systems (MES). Journal of Innovation Management, 3(4), 16-21. http://dx.doi.org/10.24840/2183-0606_003.004_0003.

D’Emilia, G., Gaspari, A., \& Galar, D. P. (2018). Improvement of measurement contribution for asset characterization in complex engineering systems by an iterative methodology. International Journal of Senvice Science, Management, Engineering, and Technology, 9(2), 85-103. http://dx.doi.org/10.4018/IJSSMET.2018040104.

Ding, B. (2018). Pharma industry 4.0: Literature review and research opportunities in sustainable pharmaceutical supply chains. Process Safety and Environmental Protection, 119, 115-130. http://dx.doi.org/10.1016/j.psep.2018.06.031.

Gunasekaran, A., Subramanian, N., \& Ngai, W. T. E. (2019). Quality management in the 21st century enterprises: Research pathway towards industry 4.0. International Journal of Production Economics, 207, 125-129. http://dx.doi.org/10.1016/j.jpe.2018.09.005.

Irani, Z., Sharif, A. M., Lee, H., Aktas, E., Topaloğlu, Z., van’t Wout, T., \& Huda, S. (2018). Managing food security through food waste and loss: small data to big data. Computers \& Operations Research, 98, 367-383. http://dx.doi.org/10.1016/j.cor.2017.10.007.

Kamble, S. S., Gunasekaran, A., \& Gawankar, S. A. (2018). Sustainable industry 4.0 framework: a systematic literature review identifying the current trends and future perspectives. Process Safety and Environmental Protection, 117, 408-425. http://dx.doi.org/10.1016/j.psep.2018.05.009.

Kampker, A., Heimes, H., Bührer, U., Lienemann, C., \& Krotil, S. (2018). Enabling data analytics in large scale manufacturing. Procedia Manufacturing, 24, 120-127. http://dx.doi.org/10.1016/j.promfg.2018.06.017.

Kozjek, D., Vrabič, R., Rihtaršič, B., \& Butala, P. (2018). Big data analytics for operations management in engineer-to-order manufacturing. Procedia CIRP, 72, 209-214. http://dx.doi.org/10.1016/j.procir.2018.03.098.

Lasi, H., Fettke, P., Kemper, H.-G., Feld, T., \& Hoffmann, M. (2014). Industry 4.0. Business \& Information Systems Engineering, 6(4), $239-242$. http://dx.doi.org/10.1007/s12599-014-0334-4.

Li, L. (2018). China's manufacturing locus in 2025: With a comparison of “made-in-china 2025" and "industry 4.0". Technological Forecasting and Social Change, 135, 66-74. http://dx.doi.org/10.1016/j.techfore.2017.05.028.

Li, X., Li, D., Wan, J., Vasilakos, A. V., Lai, C. F., \& Wang, S. (2015). A review of industrial wireless networks in the context of industry 4.0. Wireless Networks, 23(1), 23-41. http://dx.doi.org/10.1007/s11276-015-1133-7.

Lin, D., Lee, C., Lau, H., \& Yang, Y. (2018). Strategic response to industry 4.0: an empirical investigation on the Chinese automotive industry. Industrial Management \& Data Systems, 118(3), 589-605. http://dx.doi.org/10.1108/IMDS-09-2017-0403.

Melnyk, S. A., Flynn, B. B., \& Awaysheh, A. (2018). The best of times and the worst of times: empirical operations and supply chain management research. International Journal of Production Research, 56(1-2), 164-192. http://dx.doi.org/10.1080/00207543.2017.1391423.

Miller, W. J., Duesing, R. J., Lowery, C. M., \& Sumner, A. T. (2018). The quality movement from six perspectives. The TQM Journal, 30(3), 182-196. http://dx.doi.org/10.1108/TQM-10-2017-0113.

Müller, J. M., Buliga, O., \& Voigt, K. 1. (2018). Fortune favors the prepared: how SMEs approach business model innovations in industry 4.0. Technological Forecasting and Social Change, 132, 2-17. http://dx.doi.org/10.1016/j.techfore.2017.12.019.

Nascimento, D. L. M., Alencastro, V., Quelhas, O. L. G., Caiado, R. G. G., Garza-Reyes, J. A., Rocha-Lona, L., \& Tortorella, G. (2019). Exploring industry 4.0 technologies to enable circular economy practices in a manufacturing context. Journal of Manufacturing Technology Management, 30(3), 607-627. http://dx.doi.org/10.1108/JMTM-03-2018-0071.

Ngo, Q. H., \& Schmitt, R. H. (2016). A data-based approach for quality regulation. Procedia CIRP, 57, 498-503. http://dx.doi.org/10.1016/j. procir.2016.11.086.

Para, J., Del Ser, J., Nebro, A. J., Zurutuza, U., \& Herrera, F. (2019). Analyze, sense, preprocess, predict, implement, and deploy (ASPPID): An incremental methodology based on data analytics for cost-efficiently monitoring the industry 4.0. Engineering Applications of Artificial Intelligence, 82, 30-43. http://dx.doi.org/10.1016/j.engappai.2019.03.022.

Park, S. H. (1995). A new method of analysis for parameter design in quality engineering. Total Quality Management, 6(1), 13-20. http:// dx.doi.org/10.1080/09544129550035549.

Raut, R. D., Mangla, S. K., Narwane, V. S., Gardas, B. B., Priyadarshinee, P., \& Narkhede, B. E. (2019). Linking big data analytics and operational sustainability practices for sustainable business management. Journal of Cleaner Production, 224, 10-24. http://dx.doi.org/10.1016/j. jclepro.2019.03.181.

Ren, S., Zhang, Y., Liu, Y., Sakao, T., Huisingh, D., \& Almeida, C. M. (2019). A comprehensive review of big data analytics throughout product lifecycle to support sustainable smart manufacturing: a framework, challenges and future research directions. Journal of Cleaner Production, 210, 1343-1365. http://dx.doi.org/10.1016/j.jclepro.2018.11.025.

Rossit, D.A., Tohmé, F. and Frutos, M. A data-driven scheduling approach to smart manufacturing. Journal of Industrial Information Integration, 2019, 15, 69-79. http://dx.doi.org/10.1016/j.jii.2019.04.003.

Sanders, A., Elangeswaran, C., \& Wulfsberg, J. (2016). Industry 4.0 implies lean manufacturing: research activities in industry 4.0 function as enablers for lean manufacturing. Journal of Industrial Engineering and Management, 9(3), 811. http://dx.doi.org/10.3926/jiem. 1940.

Telukdarie, A., Buhulaiga, E., Bag, S., Gupta, S., \& Luo, Z. (2018). Industry 4.0 implementation for multinationals. Process Safety and Environmental Protection, 118, 316-329. http://dx.doi.org/10.1016/j.psep.2018.06.030.

Tsai, W. H., \& Lai, S. Y. (2018). Green production planning and control model with ABC under industry 4.0 for the paper industry. Sustainability, 10(8), 2932. http://dx.doi.org/10.3390/su10082932.

Tsai, W. H., Chu, P. Y., \& Lee, H. L. (2019a). Green activity-based costing production planning and scenario analysis for the aluminum-alloy wheel industry under industry 4.0. Sustainability, 11(3), 756. http://dx.doi.org/10.3390/su11030756.

Tsai, W.-H., Lan, S. H., \& Huang, C. T. (2019b). Activity-based standard costing product-mix decision in the future digital era: green recycling steel-scrap material for steel industry. Sustainability, 11(3), 899. http://dx.doi.org/10.3390/su11030899.

Yadegaridehkordi, E., Hourmand, M., Nilashi, M., Shuib, L., Ahani, A., \& lbrahim, O. (2018). Influence of big data adoption on manufacturing companies' performance: an integrated DEMATEL-ANFIS approach. Technological Forecasting and Social Change, 137, 199-210. http:// dx.doi.org/10.1016/j.techfore.2018.07.043. 